\title{
Distortion of chest movement by increased airways resistance
}

\author{
S. G O DFREY ${ }^{1}$, A. LEVENTHA L, Z. WEINTRAUB, \\ R. KATZENELSON, and N.M. CON NOLLY \\ Institute of Diseases of the Chest, London, England and the Hadassah University Hospital, \\ Jerusalem, Israel
}

\begin{abstract}
The movement of the chest during breathing has been recorded in normal and asthmatic subjects by means of electronic transducers which measured changes in anteroposterior and lateral diameters. Preliminary studies showed that exercise-induced bronchoconstriction caused distortion of the movement of the diameters in relation to each other and to volume change recorded at the mouth. Because of the thoracic gas compression which occurs during breathing, volume change at the mouth does not represent the change in chest volume and further studies were therefore undertaken in a whole-body plethysmograph. These studies showed that the addition of a resistance to the airway of a normal subject distorted the movement of one diameter (usually the anteroposterior) in relation to the other and to volume. With exercise-induced asthma, the movement of both diameters was affected with the anteroposterior lagging behind the volume change. There was an approximate linear relationship between the degree of distortion and airways resistance in the asthmatic subjects and in one normal subject. The physical sign of costal margin paradox could be related to the severity of the obstruction.
\end{abstract}

Paradoxical movement of the costal margin, with a decrease in transverse diameter relative to anteroposterior diameter, is a common physical sign in patients with obstructive lung disease (Campbell, 1969) but the observer variation in reporting its presence is considerable (Godfrey $e t$ al., 1969a). It was noted in 8 out of 16 patients with chronic obstructive lung disease, but the correlation with the severity of airways obstruction was poor (Godfrey, Edwards, Campbell, and Newton-Howes, 1970). On the other hand, Agostoni and Mognoni (1966) found that distortion of chest movement occurred in normal adults when breathing through a resistance, and the degree of distortion could be related to transpulmonary pressure changes. Connolly and Godfrey (1969) reported the results of preliminary studies of asthmatic children in whom reversible distortion of chest movement could be related to peak expiratory flow rate.

In all the previous studies, chest movement was assessed from the tidal volume change recorded at the mouth. Now it is well known that this does not record correctly the changes of chest volume owing to the compression of gas during breathing,

1Correspondence: Dr. S. Godfrey, Institute of Diseases of the Chest, Fulham Road, London S.W.3 especially in the presence of airways obstruction (Ingram and Schilder, 1966). The only reliable way to record changes of chest volume in such circum-? stances is with a whole-body plethysmograph. Simple displacement transducers can be used to record changes in chest diameter (Godfrey, Kagle, $\stackrel{\sim}{x}$ and Pride, 1969b), but they cannot be used inside $\frac{0}{3}$ a plethysmograph. The description of electromagnetic transducers which could be attached directly to the chest wall (Mead, Peterson,

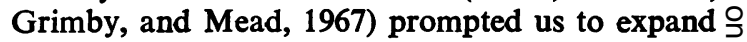
our preliminary observations by using a whole- $D$ body plethysmograph.

\section{METHODS}

Changes in the anteroposterior (AP) and lateral (Lat) diameters of the chest during breathing were recorded $\widetilde{Y}$ with electromagnetic transducers constructed after theo pattern described by Mead et al. (1967). Each trans- $\mathscr{C}$ ducer consisted of a cylinder $3 \mathrm{~cm}$ long and $1 \mathrm{~cm} \stackrel{\infty}{+}$ in diameter. It was fixed to the chest wall with ad- 0 hesive plaster with its long axis horizontal and in the $\bar{O}$ plane of the chest wall. This minimized artefacts due $\overrightarrow{\mathbb{Q}}$ to rotation of the transducer. Each diameter was mea- $\frac{C}{\mathbb{D}}$ sured by a pair of transducers, of which one was a $\varrho$ radiofrequency signal generator and the other a re- $\overline{-}$ ceiver tuned so that the two pairs did not interfere 8 
with each other. Since the maximum changes in diameter were less than $10 \%$ of the absolute diameter the change in signal was essentially linearly related to change in diameter within the range studied. The AP pair was placed in the midline at the level of the manubriosternal junction. The Lat pair was placed in the midaxillary line at a level half way between the level of the xiphoid and the costal margin. Interference from muscle contraction was found to be minimal in these positions.

In the preliminary studies on six children with asthma, the subjects were seated and breathed through a Fleish pneumotachygraph. Tidal volume recorded at the mouth was obtained by integrating the signal from the pneumotachygraph. No restriction was placed on lung volume, tidal volume or frequency. The children were studied at rest and after 6 minutes of running in order to induce bronchoconstriction (Jones, Buston, and Wharton, 1962). Peak expiratory

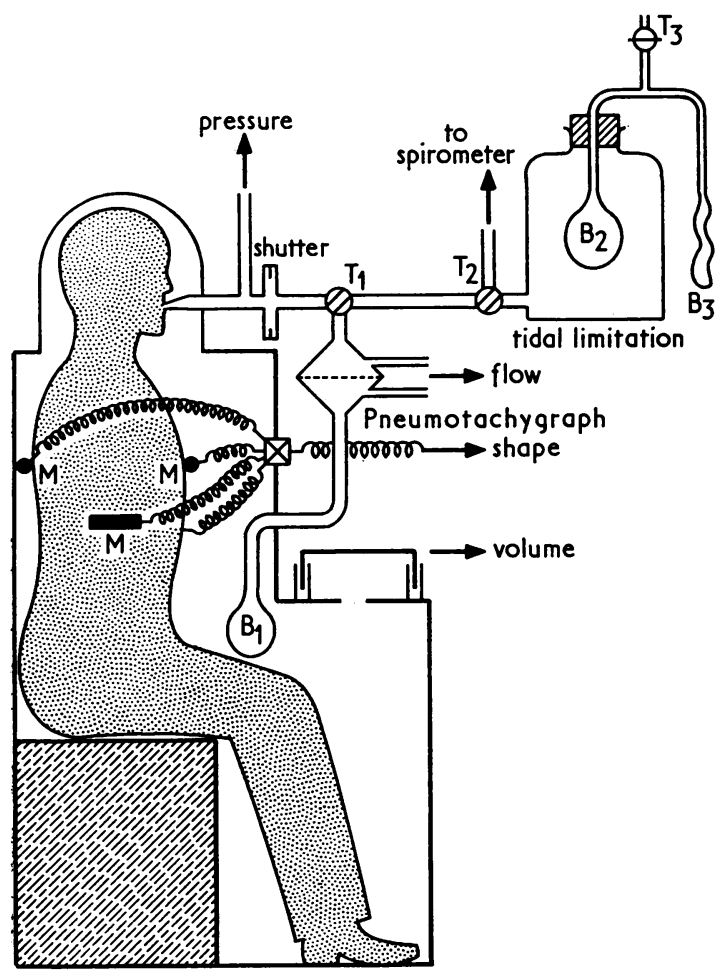

FIG. 1. Apparatus used for studying changes in chest shape and lung volume simultaneously. The subject is seated in a constant pressure whole-body plethysmograph and measurement of lung volume and airway resistance is made in the usual manner while he rebreathes from bag $B 1$. Changes in chest diameter are recorded with the transducers placed on the chest (only three shown) while the subject rebreathes from the system of bottle and linked bags (B2 and B3) which are used to limit lung volume and tidal volume as described in the text. flow rate (PEF) was measured from the pneumotachygraph record.

In all subsequent studies in normal and asthmatic subjects, the measurements were made with the subject seated inside an air-conditioned, constant pressure, whole-body plethysmograph (Mead, 1960). The arrangement of the apparatus is shown (Fig. 1). The plethysmograph could be used in its normal mode to measure lung volumes and airway resistance after the manner of DuBois et al. (1956) and DuBois, Botelho, and Comroe (1956), modified for the constant pressure machine. The subject rebreathed through a heated pneumotachygraph and tubing from a bag (B1) during the measurement of airway resistance.

Alternatively, the plethysmograph could be used to record changes in chest volume by turning tap $\mathrm{T} 1$ to enable the subject to breathe air from outside the box. During the measurements in normal subjects, tidal volume was limited by connecting the subject to the system of a bottle and linked rubber bags by means of tap T2. The subject expired into the bottle and expiration was limited by the collapse of bag B2. When he inspired from the bottle, inspiration was limited by the collapse of bag B3. The tidal volume was limited to the volume of gas enclosed in B2 plus B3 (corrected to BTPS). The electrical connexions for the chest diameter transducers passed through the wall of the box (only three of the four are shown in Fig. 1). All data were displayed on a chart recorder (Mingograf 81) from which loops were drawn relating changes in diameter to one another and to volume change. A storage oscilloscope (Tektronix) was used in the measurement of lung volume and resistance. Time delay circuits were employed to synchronize records from the different pieces of equipment.

EXPERIMENTS IN NORMAL SUBJECTS The total lung capacity (TLC), vital capacity (VC), airways resistance (Raw), specific airways conductance (SGaw), and forced expired volume in 1 second $\left(F E V_{1}\right)$ were first measured for each subject. He then expired a measured amount of gas into a spirometer via tap T2 which was so calculated as to leave his thoracic gas volume at $35 \%, 55 \%$ or $75 \%$ of TLC. He was then connected to the bottle and linked bags containing enough gas to give a tidal volume of approximately 1.2 litres. He breathed at a frequency of 16,24 or 32 breaths per minute in a regular fashion, by following the movement of a pendulum of appropriate length. The experiments were performed with and without the insertion of resistances in the airway at the mouth. The resistance of the circuit with and without the added resistances was measured with a flow generator and water manometer and the results are given (Table I). Four male subjects were studied and their physical characteristics are given (Table II).

EXPERIMENTS IN PATIENTS WITH ASTHMA Two patients with asthma (Table II) were studied while seated in the plethysmograph but no restriction was 
T A B L E I

Faר- RESISTANCE CHARACTERISTICS OF CIRCUIT

\begin{tabular}{c|c|c|c}
\hline & $\begin{array}{c}\text { Flow Rate } \\
\left(1 . \mathrm{sec}^{-1}\right)\end{array}$ & $\begin{array}{c}\text { Resistance } \\
\left(\mathrm{cm} \mathrm{H}_{2} \mathrm{O}^{-1} . \mathrm{sec}^{-1}\right)\end{array}$ & $\begin{array}{c}\text { Peak Tidal Flow } \\
\text { Rate }^{1}\left(1 . \mathrm{sec}^{-1}\right)\end{array}$ \\
\hline $\mathbf{R}_{0}$ & 0.5 & 1.7 & 2.8 \\
& 1.0 & 6.5 & 2.0 \\
$\mathbf{R}_{1}$ & 1.5 & 2.5 & \\
& 0.5 & 3.2 & 1.9 \\
$\mathbf{R}_{2}$ & 1.0 & 6.7 & \\
& 1.5 & 11.0 & 1.7 \\
$\mathbf{R}_{3}$ & 0.5 & 25.0 & \\
& 1.0 & 25.0 & \\
& 1.5 & 46.0 & 1.4 \\
\hline
\end{tabular}

The peak tidal flow rate refers to the highest recorded rates achieved during breathing by the subjects.

T A B L E I I

BODY SIZE AND PULMONARY FUNCTION RESULTS

\begin{tabular}{|c|c|c|c|c|c|c|c|c|}
\hline Subject & $\begin{array}{c}\text { Age } \\
(\mathrm{yr})\end{array}$ & $\begin{array}{l}\text { Height } \\
(\mathrm{cm})\end{array}$ & $\underset{\text { Weight }}{\text { Weight }}$ & $\begin{array}{c}\text { TLC } \\
\text { (1.) }\end{array}$ & $\begin{array}{l}\text { VC } \\
\text { (1.) }\end{array}$ & $\begin{array}{c}\text { FEV } \\
\text { (1.) }\end{array}$ & $\begin{array}{c}\text { Raw } \\
(\mathrm{cm} \\
\mathrm{H}_{2} \mathrm{O} \cdot 1^{-1} \\
\left.. \mathrm{sec}^{-1}\right)\end{array}$ & $\begin{array}{l}\mathrm{SGaw} \\
(\mathrm{cm} \\
\mathrm{H}_{2} \mathrm{O}^{-1} \\
\left.. \mathrm{sec}^{-1}\right)\end{array}$ \\
\hline $\begin{array}{l}\text { Normal } \\
\text { S.G. } \\
\text { Z.W. } \\
\text { A.L. } \\
\text { Y.K. }\end{array}$ & $\begin{array}{l}32 \\
25 \\
25 \\
34\end{array}$ & $\begin{array}{l}180 \\
168 \\
178 \\
163\end{array}$ & $\begin{array}{l}80 \\
65 \\
75 \\
67\end{array}$ & $\begin{array}{l}7 \cdot 57 \\
7 \cdot 30 \\
7 \cdot 20 \\
6 \cdot 16\end{array}$ & $\begin{array}{l}5 \cdot 50 \\
4 \cdot 70 \\
5 \cdot 20 \\
4 \cdot 60\end{array}$ & $\begin{array}{l}5 \cdot 22 \\
4 \cdot 15 \\
4 \cdot 66 \\
4 \cdot 05\end{array}$ & $\begin{array}{l}1.30 \\
2 \cdot 04 \\
1 \cdot 10 \\
1 \cdot 11\end{array}$ & $\begin{array}{l}019 \\
0 \cdot 15 \\
0 \cdot 25 \\
0 \cdot 29\end{array}$ \\
\hline $\begin{array}{l}\text { Asthma } \\
\text { Z.B. } \\
\text { N.M. }\end{array}$ & $\begin{array}{l}33 \\
12\end{array}$ & $\begin{array}{l}158 \\
147\end{array}$ & $\begin{array}{l}64 \\
33\end{array}$ & $\begin{array}{l}5.20 \\
3.44\end{array}$ & $\begin{array}{l}3 \cdot 10 \\
2 \cdot 20\end{array}$ & $\begin{array}{l}1.45 \\
1.90\end{array}$ & $\begin{array}{l}5.49 \\
2.00\end{array}$ & $\begin{array}{l}0.05 \\
0.22\end{array}$ \\
\hline
\end{tabular}

placed on lung volume, tidal volume or frequency. Measurements of lung volume, airway resistance, and chest movement were made at rest and as often as possible after 6 minutes of exercise by running. About 20 minutes after the exercise an aerosol bronchodilator was administered and the measurements were repeated. On a separate day the response to exercise was studied using a Wright peak flow meter in the manner described by Connolly and Godfrey (1970).

CALCULATIONS In order to quantitate the results, loops were drawn of one thoracic diameter against the other and of each diameter against chest volume changes, on axes representing $100 \%$ change. In the preliminary experiments, the distortion of the relationships was expressed by measuring a nominal phase delay after the manner of Agostoni and Mognoni (1966) and expressing this as a percentage such that a 'phase lag' of $180^{\circ}=100 \%$. When it became apparent that this was an approximate procedure because the motion of the chest and the volume change were far from sinusoidal, an alternative method of quantitation was used. The area of the loop was measured with a planimeter and this was expressed as a percentage of the area when the two variables were completely out of phase. It can be shown that this is twice the area of a circle whose diameter is equal to the length of the axes on which the loop is

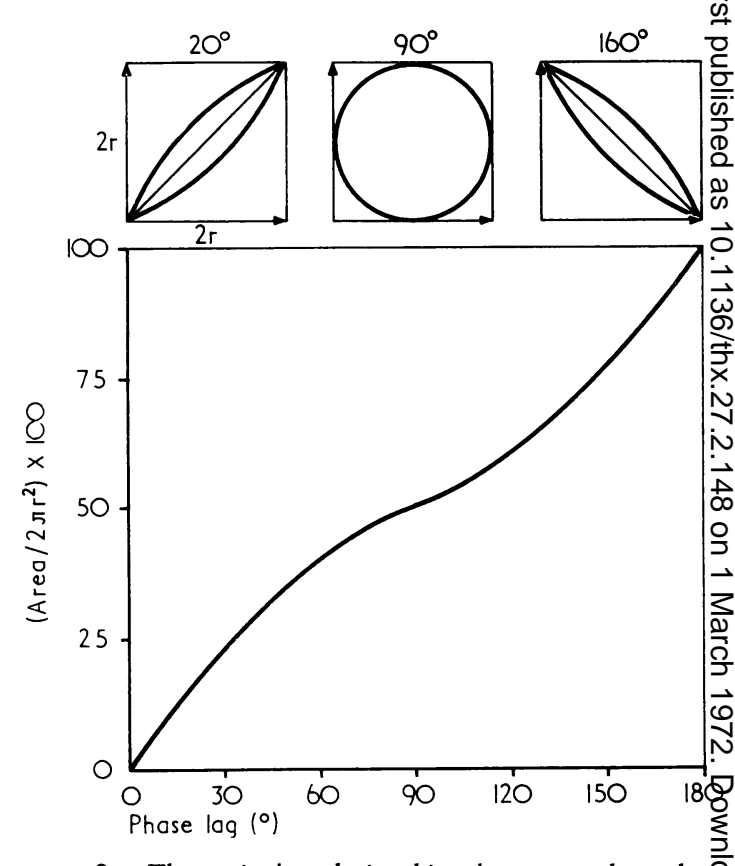

FIG. 2. Theoretical relationship between the phas relationships of two sine waves and the area of the loo obtained by plotting one function against the other (se insert above). The method of calculating the area when the long axis of the loop is negative (phase lag over $90^{\circ}$ ) described in the text. The relationship between area ant phase lag can be taken as linear within the limits of the method.

drawn. When the long axis of the loop had a nega tive slope, the relevant area was obtained by subo tracting the area of the loop from twice the area of. the circle and then expressing the result as a pei centage of the maximum area. The relationships of area to phase lag for true sine waves are shown (Fig 2).

\section{RESULTS}

The results of the preliminary studies in asthmatifo children are given in Table III. The relationshipo between movements of the AP and Lat diameters to each other and to tidal volume recorded at the mouth are given for the period of maximuin bronchoconstriction and maximum bronchodilas tion obtained in each case. There was a highly significant increase in the distortion of all the relationships at the time of maximum constrictio (lowest PEF). In most cases movement of the AP diameter was more distorted in relation to volume change than that of the Lat diameter. Costa margin paradox, in the sense of a decrease of Lag 

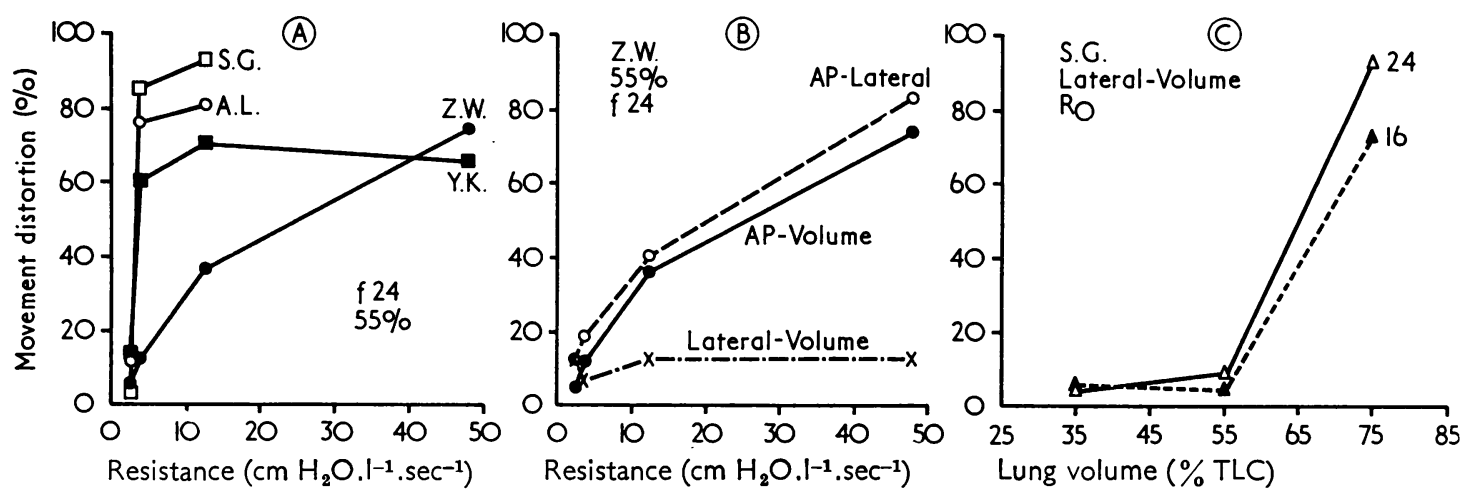

FIG. 3. (A) Distortion of movement of a chest diameter in relation to airway resistance in normal subjects with added external resistance. The AP diameter was distorted in three subjects and the lateral diameter in subject S.G. (B) Distortion in one subject in whom it increased regularly with added resistance showing that only the AP diameter was involved, the lateral-volume relationship remaining unchanged. $(C)$ Distortion produced in the lateral-volume relationship in one subject when end expiratory lung volume was increased without addition of external resistances. Note: $f=$ frequency of breathing, $R o=$ no added resistance, $55 \%=$ percentage of total lung capacity.

T A B L E I I I

RELATIONSHIP BETWEEN CHANGE IN AP AND LATERAL DIAMETER WITH EACH OTHER AND WITH CHANGE IN DIAMETER WITH EACH OTHER AND WITH CHANGE IN REN AT TIME OF MAXIMAL BRONCHODILATION (MAX PEF) AND MAXIMAL BRONCHOCONSTRICTION AFTER EXERCISE (MIN PEF)

\begin{tabular}{|c|c|c|c|c|c|c|}
\hline \multirow{2}{*}{ Child } & \multicolumn{2}{|c|}{ AP-Vol } & \multicolumn{2}{|c|}{ Lat-Vol } & \multicolumn{2}{|c|}{ AP-Lat } \\
\hline & $\begin{array}{l}\text { Max } \\
\text { PEF }\end{array}$ & $\begin{array}{l}\text { Min } \\
\text { PEF }\end{array}$ & $\begin{array}{l}\text { Max } \\
\text { PEF }\end{array}$ & $\begin{array}{l}\text { Min } \\
\text { PEF }\end{array}$ & $\begin{array}{l}\text { Max } \\
\text { PEF }\end{array}$ & $\begin{array}{l}\text { Min } \\
\text { PEF }\end{array}$ \\
\hline $\begin{array}{l}1 \\
2 \\
3 \\
4 \\
5 \\
6\end{array}$ & $\begin{array}{r}\mathbf{0} \\
0 \\
0 \\
0 \\
0 \\
11\end{array}$ & $\begin{array}{l}16 \\
26 \\
51 \\
26 \\
14 \\
47\end{array}$ & $\begin{array}{r}1 \\
3 \\
0 \\
6 \\
20 \\
0\end{array}$ & $\begin{array}{l}22 \\
26 \\
26 \\
21 \\
34 \\
15\end{array}$ & $\begin{array}{r}1 \\
3 \\
0 \\
6 \\
21 \\
12 \\
\end{array}$ & $\begin{array}{l}37 \\
52 \\
24 \\
47 \\
48 \\
32 \\
\end{array}$ \\
\hline $\begin{array}{l}\text { Mean } \\
\text { S.D. }\end{array}$ & $\begin{array}{l}2 \\
5\end{array}$ & $\begin{array}{l}30 \\
20\end{array}$ & $\begin{array}{l}5 \\
8\end{array}$ & $\begin{array}{l}24 \\
13\end{array}$ & $\begin{array}{l}7 \\
8\end{array}$ & $\begin{array}{l}40 \\
21\end{array}$ \\
\hline
\end{tabular}

diameter during inspiration, was seen in two children in whom the Lat-volume distortion exceeded $30 \%$ (more than ' $45^{\circ}$ out of phase'). However, costal paradox, in the sense of a decrease in Lat diameter while the AP diameter was increasing, was seen in all but one child (AP-Lat distortion more than $30 \%$ ).

From these preliminary studies it was concluded that acute changes in airway resistance could distort the movement of the chest, but it was not known if this was a primary effect of resistance or secondary to changes in lung volume.

The studies in normal adults using the wholebody plethysmograph were carried out to clarify the role of lung volume and resistance in producing distortion. In all four subjects, the addition of a resistance to their airway resulted in distor- tion of chest movement, which affected one diameter in relation to volume change and to the other diameter (Fig. 3A). In three subjects it was the AP diameter which was affected and in one subject it was the Lat diameter. The unaffected

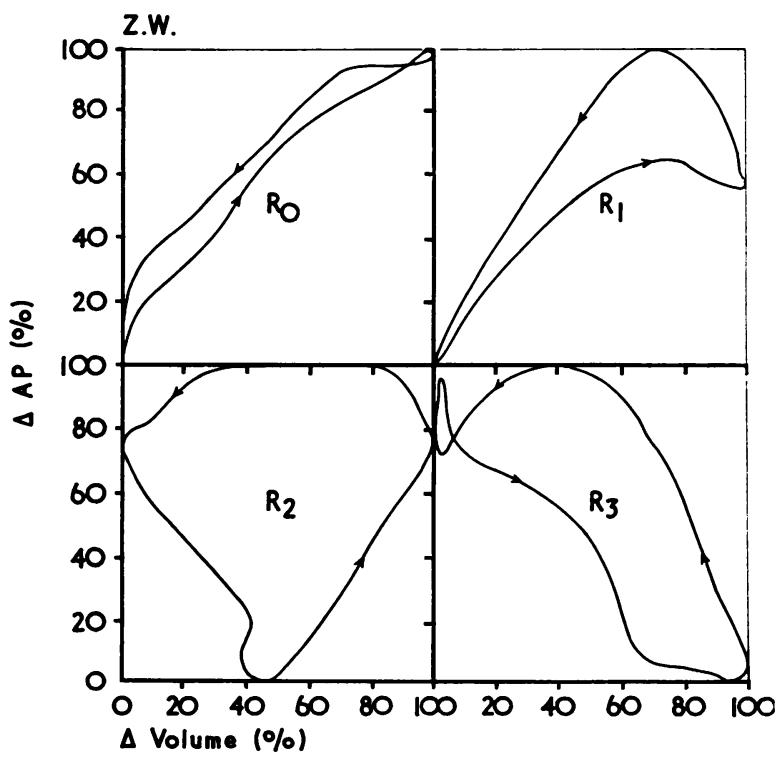

FIG. 4. Progressive distortion of relationship between movement of the AP diameter and the tidal change in chest volume in one normal subject with progressive increase in airways resistance. Note the manner in which the loop widens and then changes the direction of its long axis and compare with the insert of Fig. 2. 


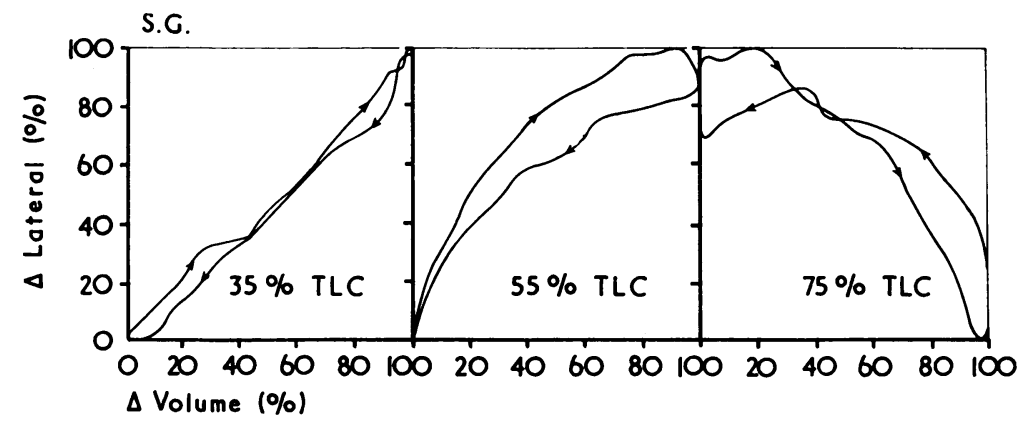

FIG. 5. Distortion of relationship between movement of the lateral diameter and tidal change in chest volume in one normal subject breathing at different levels of lung volume (functional residual capacity). Total airways resistance was $4 \mathrm{~cm}$ $\mathrm{H}_{2} \mathrm{O} \cdot \mathrm{l}^{-1} \cdot \mathrm{sec}^{-1}$ and the frequency was 16 breaths per minute.

diameter usually retained its normal relationship to volume change (Fig. 3B). In three subjects the distortion appeared with the smallest added resistance and did not increase significantly with further loading, but in one subject the distortion did increase with the added load (Fig. 3B). Lung volume had little effect on the relationships in three of the subjects, but even with no added resistance one subject showed marked distortion at high lung volumes (Fig. 3C). Frequency did not significantly affect any of the results. The distortion due to added resistance in all cases and due to high lung volume in one subject was enough to produce true paradox between the affected diameter and volume and between the two diameters. The long axis of the loop changes direction (Figs 4 and 5).

Two patients with asthma completed the studiess in the plethysmograph before and after exercise and in each case the results were very similaro After exercise, there was an increase in Raw, of fall in SGaw, and a fall in PEF. There was alse some increase in residual volume (RV) and a fali in vital capacity (VC). All these changes werळ greatest at about 5 minutes after stopping exercise. in the child and 10 minutes after stopping in the adult (Figs 6A and 7A). The changes began to reverse spontaneously and the process was com pleted by the administration of an aeroso 1 . bronchodilator. At the same time as the resistance्E
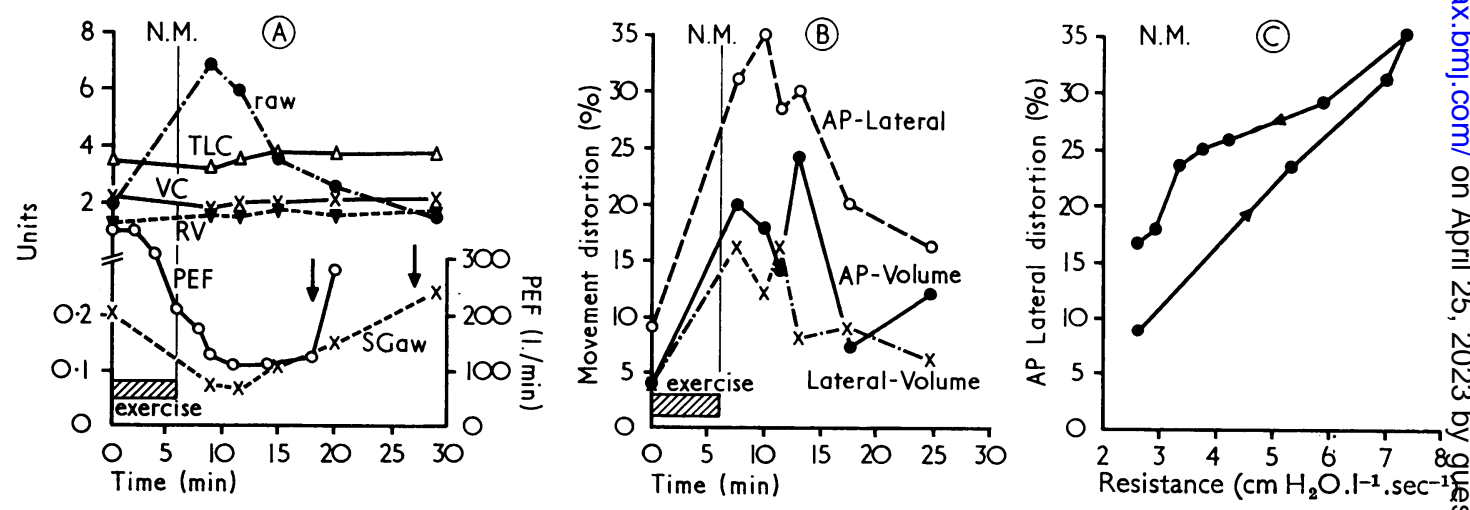

FIG. 6. Changes due to exercise in an asthmatic child. The lung volumes and airways resistance before and after 6 minutes of running are shown in relation to time $(A)$. The symbols are those used in the text; the units are as follows: Raw $\bar{D}$ $\mathrm{cm} \mathrm{H}_{2} \mathrm{O} . \mathrm{l}^{-1} . \mathrm{sec}^{-1} ; \mathrm{SGaw}, \mathrm{cm} \mathrm{H}_{2} \mathrm{O}^{-1} . \mathrm{sec}^{-1} ; \mathrm{PEF}, 1 \mathrm{~min}^{-1} ; \mathrm{TLC}, \mathrm{VC}$, and $\mathrm{RV}$ all litres. The arrows indicate the administration of an aerosol bronchodilator. Note that the PEF was measured on a different occasion from all the other parameters The distortion of movement of the chest diameters in relation to each other and to tidal change in chest volume during the same period is also shown $(B)$. The distortion between the movement of the diameters in relation to the total airwas resistance of the patient plus apparatus is given $(C)$. The distortion, i.e., costal paradox, was approximately proportionab to the resistance. 

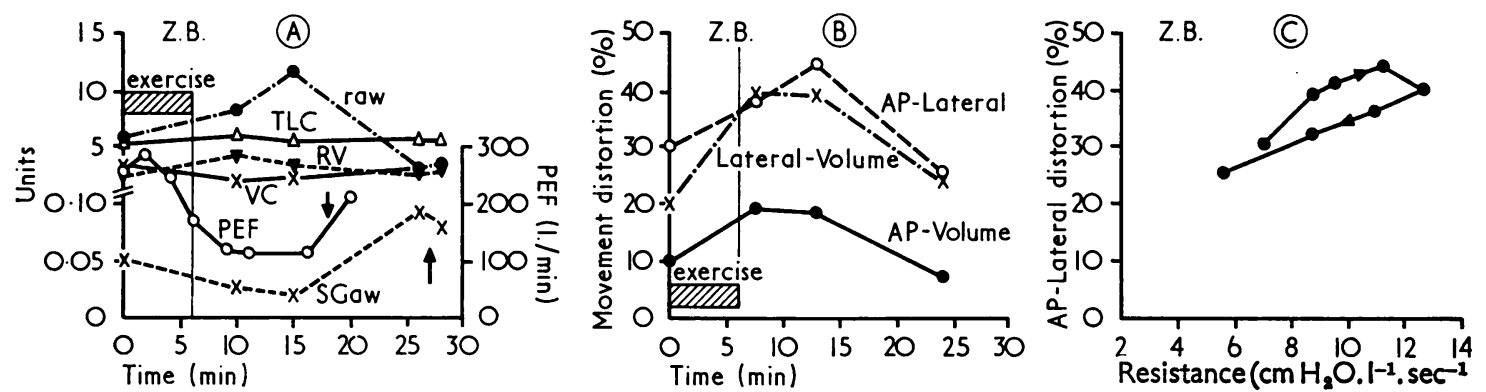

FIG. 7. Changes due to exercise in an asthmatic adult. The symbols and interpretation are the same as those in Figure 6.

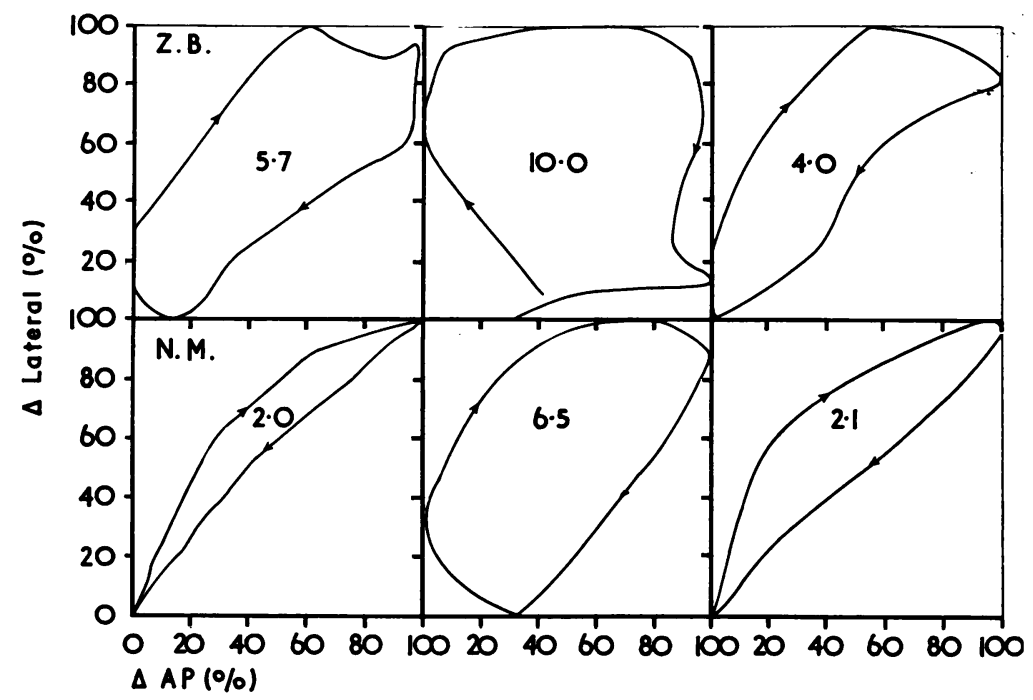

FIG. 8. Movement of the lateral diameter plotted against the movement of the AP diameter for two asthmatic subjects before and after exercises. The numbers in the centre of the loops are the airways resistance at the time of the measurement. The loops widen when the resistance is highest.

changed, distortion occurred in the movement of both $\mathrm{AP}$ and Lat diameters in relation to chest volume change and to each other (Figs 6B and 7B). The relationship between AP-Lat distortion and airways resistance (subject plus apparatus) at corresponding times have been plotted in Figs $6 \mathrm{C}$ and $7 \mathrm{C}$. As the resistance increased and then decreased after exercise, the chest movement distortion also increased and decreased, though not quite symmetrically. The change in resistance was clearly reflected in a change in the degree of AP. Lat distortion. This can also be seen from the change in area of the relevant loops (Fig. 8).

\section{DISCUSSION}

This study has shown that acute changes of airways resistance can distort the pattern of movement of the chest in both normal subjects and patients with asthma. The exact quantitation of the distortion is rendered difficult by the fact that changes of chest diameter and of lung volume are not sinusoidal functions. The assumption that the loops could be taken as representing sinusoidal functions (Agostoni and Mognoni, 1966) must lead to analytical errors or the omission of the majority of loops, which do not fit this pattern, 
from any calculations. We believe that the simple expedient of measuring the area of the loop in the manner described gives a better indication of distortion and allows many more representative breaths to be used.

The studies reported here in normal and asthmatic subjects and the studies in normal subjects described by Agostoni and Mognoni (1966) all agree in finding that airways obstruction distorts the AP-Lat diameter relationship. In some normal subjects and the two asthmatics studied in detail here, the distortion was proportional to the resistance. However, because of the considerable compression of gas within the thorax during breathing in the presence of increased airways resistance (Ingram and Schilder, 1966), no valid conclusions can be drawn about the relationship between diameter change and volume change when the latter is recorded at the mouth, as in our preliminary studies and in those of Agostoni and Mognoni (1966). In our preliminary report (Connolly and Godfrey, 1969) it was thought that AP diameter change preceded volume change in the presence of added resistance, but from our present studies in the whole-body plethysmograph it was clear that, in this situation, the diameter change lags behind the change in thoracic gas volume (anticlockwise loops, e.g., Fig. 4). This might suggest that initial expansion of lung volume in the presence of increased resistance is affected by descent of the diaphragm, but additional measurements of change in diameter of the abdomen would be needed to confirm this. In normal subjects it appeared that only one diameter (usually the AP) was distorted in relation to volume change, but in the asthmatic patients both diameters were affected. This may have been due to individual variation since in one normal subject the Lat diameter was more affected than the AP.

Breathing at high lung volume produced distortion in only one subject in the present study. A similar effect of lung volume was also seen in some normal subjects previously studied by Godfrey et al. (1969b). In our present studies on normal subjects, lung volume and tidal volume were fixed by the linked bag system and hence volume effects were separated from resistance effects. In the studies of normal subjects by Agostoni and Mognoni (1966) and in the present studies in asthmatics, no such restriction was used. However, the change in lung volume in asthmatics studied in the plethysmograph was relatively small (Figs 6A and 7A) and could not have been the cause of the distortion of chest movement. It should be noted that plethysmographic investiga- tions of asthmatic patients require very consider- $\frac{7}{0}$ able cooperation, and some other patients who 을 were previously shown to develop post-exercise $\frac{\bar{\sigma}}{\sigma}$ bronchoconstriction failed to do so when studied $\stackrel{\varnothing}{\circ}$ in the plethysmograph and also failed to develop distortion of chest movement. This was presum- क ably due to increased adrenergic stimulation from natural anxiety. In no case did constriction $\vec{\overrightarrow{ }}$ develop without distortion of movement or vice $\stackrel{\omega}{\omega}$ versa.

We conclude that added airway resistance distorts the movement of the chest in such a way that iv movement of the AP diameter lags behind the chest volume change in both normal subjects and $\underset{\infty}{\infty}$ asthmatics. Distortion of the AP-Lat diameter re- 을 lationships during breathing produces the clinical sign of costal paradox and is proportional to the $\bar{z}$ severity of the airways obstruction in asthmatic subjects. Since it has been shown that there is a poor correlation between airways obstruction and $\vec{\varphi}$ physical signs such as rhonchi (Godfrey et al., N 1970) the measurement of this distortion by means of transducers attached directly to the chest wall should be useful for monitoring attacks of asthma. This is especially so in the case of small children who are unable to cooperate with conventional lung function tests.

\section{REFERENCES}

Agostoni, E., and Mognoni, P. (1966). Deformation of the chest wall during breathing efforts. J. appl. Physiol., 21, 1827.

Campbell, E. J. M. (1969). Physical signs of diffuse airways obstruction and lung distension. Thorax, 24, 1.

Connolly, N. M., and Godfrey, S. (1969). Changes of chest configuration during breathing in children with reversible airways obstruction. Clin. Sci., 37, 567.

(i970). Assessment of the child with asthma. J. Asthma Res., 8, 31 .

DuBois, A. B., Botelho, S. Y., Bedell, G. N., Marshall, R. and Comroe, J. H. (1956). A rapid plethysmographic method for measuring thoracic gas volume: a comparison of with a nitrogen washout method for measuring functional residual capacity in normal subjects. J. clin. Invest., 35, 322.

Comroe, J. H. (1956). A new method for measuring airway resistance in man using a body plethysmograph: values in normal subjects and in patients with respiratory disease. J. clin. Invest., 35, 327.

Godfrey, S., Edwards, R. H. T., Campbell, E. J. M., Armitage, P., and Oppenheimer, E. A. (1969a). Repeatability of physical signs in airways obstruction. Thorax, 24, 4.

,,--- , and Newton-Howes, J. (1970). Clinical and physiological associations of some physical signs observed in patients with chronic airways obstruction. Thorax, 25, 285.

-, Kagle, L. E., and Pride, N. B. (1969b). Movements of the chest wall during breathing. J. Physiol., 202, $11 \mathrm{P}$. 
Ingram, R. H., and Schilder, D. P. (1966). Effect of thoracic gas compression on the flow-volume curve of the forced vital capacity. Amer. Rev. resp. Dis., 94, 56.

Jones, R. S., Buston, M. H., and Wharton, M. J. (1962). The effect of exercise on ventilatory function in the child with asthma. Brit. J. Dis. Chest, 56, 78.
Mead, J. (1960). Volume displacement body plethysmograph for respiratory measurements in human subjects. $J$. appl. Physiol., 15, 736.

Peterson, N., Grimby, G., and Mead, J. (1967). Pulmonary ventilation measured from body surface movements. Science, 156, 1383. 